\title{
O IV Encontro Regional de Estudantes Indígenas da Região Sul (EREI SUL): a UFPR como território indígena
}

JACIELE NYG KUITÁ KAINGANG

LAYS GONÇALVES DA SILVA

PAOLA ANDRADE GIBRAM

Organizado, gerido e formulado por estudantes indígenas, o Encontro Regional de Estudantes Indígenas da Região Sul (EREI Sul) ocorreu em sua 4a edição entre os dias 27 e 29 de novembro de 2019, na Universidade Federal do Paraná (UFPR), na cidade de Curitiba. Durante os três dias de evento, a UFPR, pela primeira vez, recebeu em seus corredores e saguões cerca de cem indígenas vindos de vários territórios do Sul do Brasil e demais regiões. Ao todo, o evento contou com aproximadamente 150 participantes, uma vez que não indígenas também participaram como voluntários e ouvintes. As mesas e debates que centralizaram o evento ocorreram na tradicional sala Homero de Barros, localizada no Prédio Dom Pedro I, no Campus da Reitoria. As mesas foram compostas exclusivamente por indígenas que trouxeram suas experiências como profissionais da saúde e educação, lideranças políticas, estudantes de pós-graduação, atuantes do movimento indígena nacional, do movimento de juventude e de mulheres indígenas. Esteve também presente o coletivo de juventude indígena Kaingang Nẽn Ga, da Terra Indígena Apucaraninha (PR). Ao longo desses três dias, trouxeram seus cantos, suas vozes, seus movimentos para dentro da Universidade, ampliando ainda mais a potência desse evento. 


\section{Apresentando o EREI}

O EREI Sul é um evento de mobilização estudantil indígena, que foi inicialmente organizado por integrantes dos PET-Indígenas da região Sul ${ }^{1}$, ligados à Universidade Federal de Santa Maria (UFSM) e à UFPR -- Setor Litoral. Sua criação se deu a partir da participação dos estudantes indígenas dessa região no III ENEI - que ocorreu na UFSC, em 2015 - e da percepção desses estudantes sobre a necessidade de se organizarem regionalmente. Seus objetivos iniciais eram, portanto, fomentar a participação política, a autonomia, a autoreflexão sobre o estar na universidade e a união dos estudantes indígenas no contexto regional, bem como discutir questões que lhes são consideradas específicas. Fortalecendo essa articulação em rede, os estudantes precursores desse evento consideravam que assim estariam mais preparados e bem fundamentados para levar suas pautas e demandas para o encontro nacional.

A primeira edição do EREI ocorreu em Santa Maria, na UFSM, no ano de 2016 e o II EREI ocorreu na UFRGS, em Porto Alegre, em 2017. Os acadêmicos indígenas que participaram desses dois primeiros eventos, defendiam um tema um tanto emblemático "A Universidade como território indígena: pensando caminhos para interculturalidade”. Já o III EREI ocorreu na UFSC, em Florianópolis, em 2018, e teve como tema "Violências: social, cultural e institucional. A presença indígena nos territórios da aldeia à universidade”. A partir do princípio de rotatividade dos locais de realização dos encontros, foi decidido na plenária final desse último evento que o IV EREI seria sediado no estado do Paraná. E posteriormente, em reunião presencial entre os estudantes das universidades estaduais e das federais do estado, encaminhou-se que a UFPR receberia a nova edição.

O evento desse ano (2019) teve como tema "Acadêmicos indígenas em resistência: trajetórias, direitos, territorialidade epistêmica". Dos cerca de 150 participantes, aproximadamente 30 indígenas eram estudantes da UFPR - de cursos de Curitiba e Litoral, com destaque aos indígenas da turma de Educação do Campo/Campus Litoral - e 70 vieram de outras localidades, entre estudantes e egressos ligados à UFRGS, UFSC, Unochapecó, UFFS, escolas indígenas (Colégio Estadual Indígena Benedito Rokag/ TI Apucaraninha e a Eief Fen no, TI Toldo Chimbangue), lideranças indígenas Kaingang, Guarani e Xokleng dos três estados do Sul do Brasil. Fizeram-se presentes também palestrantes de outras regiões, como Márcio Bakairi (UFRJ) e Cristiane Julião Pankararu (Museu Nacional/ UFRJ), ambos estudantes de pós-graduação em Antropologia Social (mestrado e doutorado, respectivamente).

\section{Como ocorre? Questões de organização}

Como qualquer evento de mobilização regional, para que ocorresse, o IV EREI-Sul demandou muitos esforços dedicados a sua organização. Gastos com alimentação, transporte dos convidados, estadia - básicos para a concretização do evento -, demandaram o rastreamento incessante de parceiros que pudessem apoiar sua realização. Assim, formou-se uma comissão organizadora, que além das ques-

1 Existem apenas dois Programas de Ensino Tutorial (PET) ligados ao edital do MEC “Conexões de Saberes" no sul do Brasil. Um na UFSM e outro na UFPR, denominados “PET Indígena Nande Reko” e "PET Litoral Indígena”. 
tões de cunho prático, responsabilizou-se pelas questões referentes às temáticas a serem tratadas nas mesas, quem seriam os convidados para os debates e quais seriam os espaços ocupados na Universidade. Essa Comissão Organizadora foi composta por estudantes indígenas da UFPR, universidade sede, e contou com o apoio de indígenas de outras universidades da região Sul bem como de parceiros não indígenas - dos quais alguns atuaram junto às voluntárias nos dias de evento.

Formada por um coletivo mais amplo², a comissão foi tomada à frente por Jaciele Nyg Kuitá Fideles e Ana Carolina Neres (ambas Kaingang, graduandas do curso de Serviço Social/ UFPR-litoral), Tainara Ganin de Oliveira (Kaingang, graduanda do curso de Terapia Ocupacional), Ivanisia Ruiz (Kaixana, graduanda do curso de Direito/ UFPR) e Luís Carlos Rãkag Dias (Kaingang, graduando do curso de Educação Física/ UFPR).

Para a estadia dos participantes, a Comissão Organizadora conseguiu o apoio do Sindicato dos Bancários de Curitiba e Região, que ofereceu como alojamento a Sede Campestre localizada em Piraquara, município da Região Metropolitana de Curitiba. Outros sindicatos e organizações não-governamentais ${ }^{3}$ apoiaram com recursos para o transporte de convidados e alimentação dos participantes do evento - a qual foi negociada com o Restaurante Universitário da UFPR. Por meio do diálogo com as diversas organizações e sindicatos, alcançaram-se assim os recursos necessários para a compra dos cafés da manhã, gastos com material gráfico, custos diversos com gasolina para deslocamentos da comissão organizadora e demais urgências que surgiram ao longo do evento.

A desenvoltura e criatividade da comissão para buscar os apoios financeiros contou, também, com outra frente de atuação: as rifas. Doações de brindes pelo grupo PEITA.ME e de artesanatos por indígenas apoiadores à organização do EREI tornaram-se prêmios de rifas que foram vendidas para arrecadação de recursos, e grande parte das demandas foi custeada com essa iniciativa. Para atrair colaboradores, as organizadoras circularam pelas salas de aula nos diferentes campi da universidade e divulgaram os prêmios pela internet. Vale ainda ressaltar que a internet foi uma importante ferramenta para a organização do evento. Além do grupo do whastapp acima mencionado, as organizadoras criaram uma página no facebook e um perfil no instagram, por meio dos quais divulgavam as informações pertinentes, fizeram o sorteio ao vivo e transmitiram online as atividades das mesas e debates.

\footnotetext{
2 Este coletivo mais amplo comunicava-se por meio de um grupo de whatsapp, do qual faziam parte: Aline, Guarani Nhandeva, estudante de Psicologia; Euller, Kaiowá, estudante de Odontologia; Luciana, Terena, estudante de Direito; Kauane, Guarani Nhandeva, estudante de arquitetura; Natana, Kaingang, estudante de enfermagem; Jaqueline, Kaingang, estudante de administração. Alguns estudantes indígenas como Camila, Kaingang da Aldeia Urbana Kakané Porã e Robson, Tukano de São Gabriel da Cachoeira - AM, decidiram sair da organização mais direta, porém, acompanharam o evento. Além dos participantes indígenas, a Comissão contou com alguns colaboradores não indígenas: Lays Gonçalves, mestre em Antropologia; Amanda, estudante de design; Mateus, estudante de Direito, ligado ao Diretório Central dos Estudantes; Mauro, representante da FUNAI; Gustavo, estudante de Direito, do Diretório Central dos Estudantes.

3 Além da UFPR por meio de suas Pró-Reitorias, participaram como apoiadores do evento o Centro Acadêmico de Serviço Social, as ONGs Instituto Socioambiental (ISA) e COMIN, os sindicatos APUFPR, o SINTRACON, SINDIJUS, SISMMAC, SINSEP, e dois mandatos políticos.
} 


\section{Programação, convidados, temas debatidos}

As atividades do IV EREI Sul ocorreram ao longo dos dias 27, 28 e 29 de novembro, nos períodos da manhã e da tarde. À noite, os convidados dirigiam-se ao alojamento. No primeiro dia, pela manhã, foram realizados os credenciamentos dos participantes, que ganharam uma pasta com caderno, caneta, uma folha com a programação e um copo estilizado com a imagem do evento. Às 9h30, com os convidados reunidos na sala Homero de Barros, as organizadoras do evento convidaram os representantes das instituições colaboradoras para concentrarem-se à mesa central, para que fossem feitos os devidos agradecimentos. Na sequência, o coletivo Nẽn Ga foi convidado para realizar seus cantos/ danças/rituais, preenchendo a sala com a potência de suas vozes, seus corpos e movimentos.

$\mathrm{Na}$ sequência foi realizada a mesa de abertura, para a qual foram convidadas lideranças indígenas de diversas regiões. O nome da mesa era: "Lideranças indígenas e estudantes indígenas: olhares e perspectivas”. Estavam presentes nessa mesa Danilo Braga, professor de História, doutorando pela UFRGS; Gilda Kuitá, liderança da TI Apucaraninha (PR); Marciano Rodrigues, representante da APIB; Ivan Kaingang, liderança da TI Rio das Cobras, Cristiano Jorge Goje, representante do coletivo Nẽn Ga, Andreia Takuá, Coordenadora do FPCondisi; Vanisse Domingos, pedagoga atuante na educação indígena no Oeste de Santa Catarina, da TI Toldo Chimbangue; Eunice Kerexu, liderança Guarani da TI Morro dos Cavalos. Participaram também o artista Jaider Esbell e sua mãe, Bernaldina Macuxi, da TI Raposa Serra do Sol, os quais estavam participando de um evento ocorrido no MusA ${ }^{4}$.

As questões suscitadas por essa primeira mesa, foram destacadas por Nyg, que, como mediadora, apontou a importância de se refletir sobre as estratégias necessárias para fomentar o contato dos estudantes indígenas com seus territórios e lideranças locais. Por perceber o fato de existirem muitos estudantes indígenas que não estão tendo uma orientação adequada a sua permanência e formação na universidade, questiona: “Por que estamos na Universidade? Para quem?”. Para que os estudantes indígenas não sejam cooptadas por uma lógica colonizadora, etnocêntrica e individualista de formação e produção acadêmica, percebe a necessidade urgente de que os conhecimentos indígenas sejam trazidos, em sua pluralidade, para dentro das instituições de ensino - desde as escolas primárias até às universidades.

Nyg destacou a relação entre os conhecimentos indígenas e não indígenas, e que a noção de interculturalidade deve ser profundamente criticada - uma vez que o significado dessa palavra ainda está distante da realidade vivida pelos indígenas nas universidades. Sua percepção é de que a interculturalidade na prática é atualizada por meio de uma assimetria inerente à imposição do conhecimento branco nas instituições de ensino. Percebe-se, portanto, ser distante a ideia de trocas mútuas de conhecimentos, reciprocidades nas formas de ensinar, aprender e circular conhecimentos. Além disso, percebe-se como ponto crítico o fato de essa categoria pressupor apenas duas culturas: a dos brancos e a dos indígenas (essa última tomada de forma genérica). Assim, propõe-se que a universidade invista não na interculturalidade, mas na garantia da pluralidade de conhecimentos, no respeito às singularidades

4 Lançamento da exposição de Jaider Esbell e Gustavo Caboco "Netos de Makunaimi: encontros de arte indígena contemporânea". 
da presença indígena na universidade. Aponta-se assim, a necessidade urgente de que a Universidade perceba que as formas de elaboração e transmissão dos saberes indígenas, amplamente diversos, podem fazer parte da construção contínua dos conhecimentos e da própria instituição.

A segunda mesa tematizou questões referentes à saúde indígena, sendo intitulada "Saúde indígena: desafios e enfrentamentos inerentes à promoção da saúde mental e medicina tradicional no contexto institucional da Secretaria Especial de Saúde Indígena (SESAI)". Participaram dessa mesa Eunice Kerexu; Adroaldo Fidélis (Duco Kaingang), que é mestrando em educação e coordenador Pedagógico da Secretaria de educação de SC; Jaqueline Kuitá, enfermeira na CASAI em Curitiba ${ }^{5}$ e Andrea Takuá. Nesta mesa, todos os participantes chamaram a atenção para os perigos da municipalização da saúde indígena e a extinção da SESAI. Evidenciando o caráter de movimento político do evento, os palestrantes invocaram os estudantes indígenas a estarem atentos aos trâmites referentes aos direitos indígenas no congresso nacional, a conhecerem de perto seus direitos conquistados e aliarem-se à luta do movimento indígena nacional pela saúde. A municipalização teria consequências desastrosas para as vidas das populações indígenas, uma vez que os interesses municipais muitas vezes são divergentes, senão contrários, às demandas e especificidades indígenas em relação aos cuidados com a saúde. Os participantes colocaram também que são muitas as dificuldades em praticar os cuidados na saúde de forma específica e respeitosa às realidades indígenas, apontando as muitas imposições do sistema de saúde formal dos não indígenas. No entanto, é unânime a ideia de que mesmo com todas as dificuldades, a SESAI foi uma conquista dos povos indígenas e sua extinção apontará para um grande retrocesso nos direitos.

Ainda durante os debates dessa segunda mesa, a qual foi mediada por Tainara, colocou-se a necessidade de se pensar de que forma os acadêmicos indígenas podem se aproximar das questões referentes à saúde indígena nos territórios, visando uma melhoria de qualidade nos atendimentos e nas políticas públicas condizentes. Outros pontos levantados foram referentes a questões de saúde mental dos indígenas, as quais foram relacionadas a problemas sociais decorrentes do contato, tendo como consequência latente o alcoolismo. Os problemas contemporâneos referentes à saúde mental indígena foram, então, relacionados ao afastamento do "ser indígena”, à desvinculação com o território e com a ancestralidade de cada povo.

A terceira mesa foi intitulada "Políticas afirmativas e povos indígenas, os rumos da universidade pública: balanço, perspectivas e desafios”. Compuserama mesa Adroaldo Fideles (Duco Kaingang), Luana Kaingang, graduanda em Odontologia pela UFRGS e Márcio Bakairi, mestrando em Antropologia Social pelo IFRJ. No decorrer dessa mesa foram apresentadas conquistas por parte dos indígenas no que concerne às políticas de ingresso e permanência dos estudantes nas universidades, sendo, no entanto, sempre enfatizada a necessidade de "se avançar". Um dos pontos salientados pelos participantes do debate foi de que é preciso investir na desconstrução das verdades impostas aos próprios estudantes indígenas, uma vez que percebe-se que muitos ainda entram na universidade sem estarem cientes ou orientados sobre seus papéis e especificidades enquanto estudantes indígenas.

5 Casa de Saúde Indígena (CASAI) localizada na sede do Distrito de Saúde Indígena Litoral Sul (DSEI Litoral Sul). 
A quarta mesa, que abriu os debates do segundo dia do evento, ocorreu após a roda de cantos/ danças/rituais do coletivo Nẽn Ga, que novamente ocupou a sala Homero de Barros com a força de suas vozes e movimentos. Essa mesa tematizou a questão considerada fundamental para todas as questões em debate no que concerne aos movimentos indígenas: a territorialidade. Intitulada "Território e resistência: desenvolvimentismo e as violações dos direitos dos Povos Indígenas, enfrentamentos, estratégias. protocolos de consulta prévia”, essa mesa contou com a presença de Lucimara Patté, do povo Xokleng, graduada em Direito pela UFSC; Ivan Bribis, Kaingang, formado em Direito pela UEM; Cristiano Goje, Kaingang, representante do Nẽn Ga; Mauro Casemiro, graduado em Pedagogia e professor na TI Iraí, e Marcolino Silva, Guarani, liderança da aldeia Araçaí. A principal questão apontada pelos palestrantes foi a relação entre a redução territorial somada às violações sofridas nos territórios, que vêm sendo atualizadas por medidas inconstitucionais como a PEC 215. As remoções forçadas - a exemplo os Xetá - e as reduções territoriais à "canetada” foram fatores ressaltados nas discussões sobre o referenciamento do Marco Temporal (PEC 215) às terras ocupadas em 1988.

Todos os participantes dessa quarta mesa enfatizaram que os territórios são o primeiro direito que precisa ser assegurado, pois sem terra não é possível que haja saúde, educação e bem viver. Destacou-se também que, embora as realidades nas regióes do Brasil sejam diferentes no que tange os empreendimentos, a consulta prévia e informada, garantida pela Convenção no 169 da OIT, precisa ser respeitada. Outro elemento trazido foi a desarticulação e o esfacelamento da FUNAI por parte das ações do atual governo, enquanto órgão responsável pelas demarcações, salientou-se que a extinção da FUNAI significaria o fim das demarcações. A interdependência de todos os temas trazidos nas mesas anteriores com a questão territorial permeou as falas dos palestrantes e o debate posterior. Foram muito enaltecidas as lutas dos mais velhos, que inclusive garantiram os direitos específicos que constam na Constituição Federal de 1988. Ao fim da mesa, os estudantes indígenas foram convocados enfaticamente a aliarem-se às lutas por territórios empenhadas pelas lideranças, direcionando seus conhecimentos, apropriações de tecnologias e outras ferramentas a favor do movimento indígena mais amplo, dando continuidade à trajetória de resistência de seus ancestrais.

Importante ressaltar que, antes de dar prosseguimento ao texto, o IV EREI Sul foi construído, pensado e articulado com amplo protagonismo das mulheres. A comissão organizadora foi quase inteiramente formada por mulheres, as quais tomaram a frente de todos os processos de decisão e construção. Assim sendo, essa edição do EREI apresentou-se como uma instância de formação política e de articulação de mulheres indígenas, parte de um processo que vem ocorrendo de forma mais ampla com os povos indígenas de todo o território brasileiro. Desta forma, a quinta mesa trouxe mulheres indígenas que têm atuado nos espaços públicos e políticos, assumindo lugares de fala de grande abrangência, ocupando espaços de decisão para o movimento indígena e para seus próprios territórios de origem. Intitulada "A atuação das mulheres indígenas no espaço político: direitos e bem viver indígena, o sagrado da existência em movimento", essa mesa contou com a participação de Cristiane Pankararu, Lucimara Patté, Gilda Kuitá, Vanisse Domingos, e teve como mediadora Nyg Kuitá (todas acima apresentadas). 


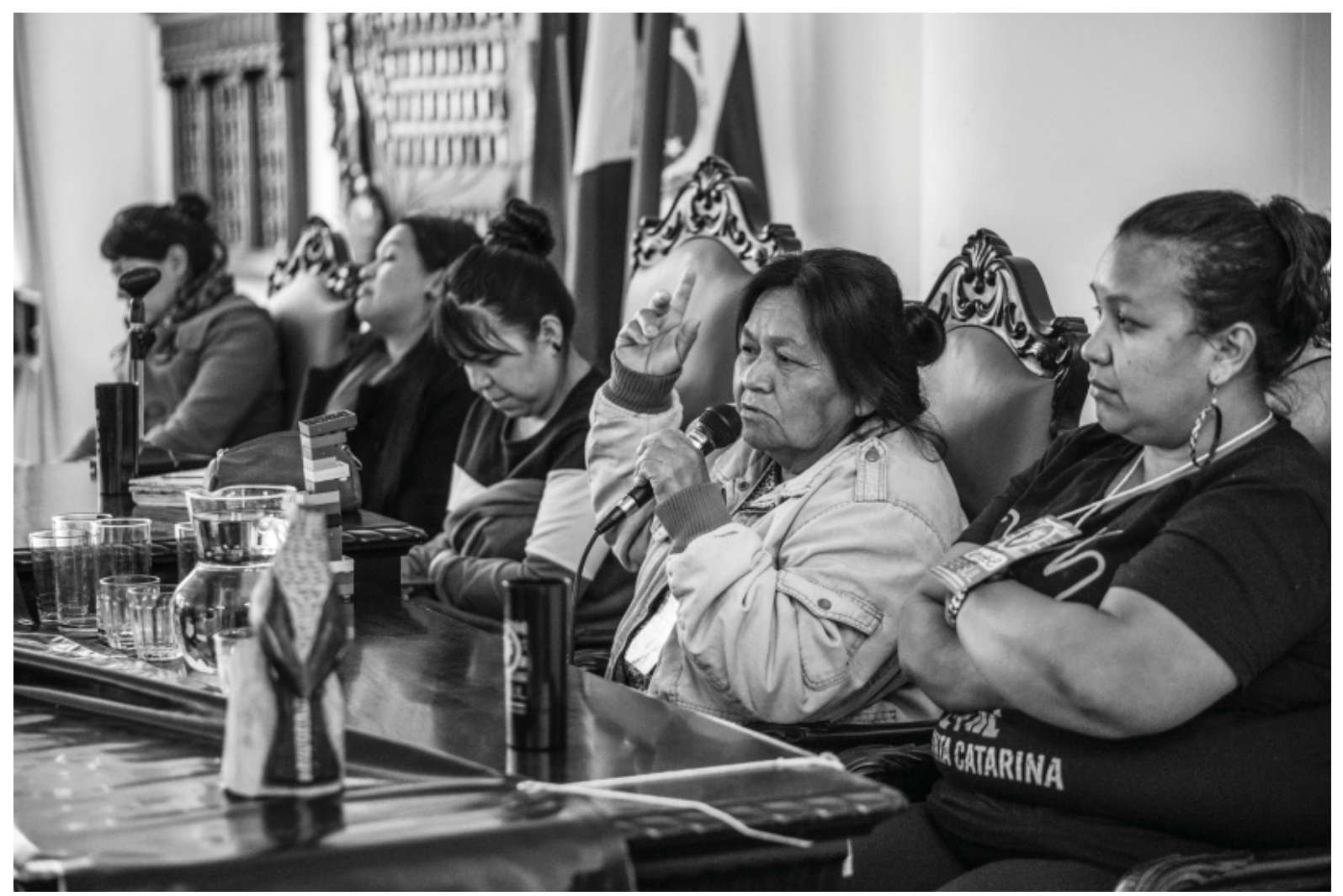

Imagem 1: Mesa mulheres indígenas

Fonte: Arquivo do MAE-UFPR. Autor: Douglas Fróis, novembro de 2019

Um dos pontos trazidos pelas palestrantes foi de que a ocupação do espaço político pelas mulheres indígenas implica em uma retomada aos lugares que sempre foram ocupados por elas, em seus territórios ou fora deles. Salientam com isso que o machismo e as práticas de silenciamento e violência sistemática contra as mulheres não são constituintes das culturas dos povos indígenas. Para consolidarem essa retomada de espaços e formas de existência, indicam suas ligações com o plano espiritual e com o plano sagrado de seus corpos e territórios - algo que consideram imprescindível para o empoderamento contemporâneo e para a atuação como multiplicadoras do movimento indígena. "Nós mulheres indígenas até em silêncio estamos em movimento" - disse Nyg, ao apresentar suas questões como mediadora da mesa. Dentre as muitas questões apresentadas e debatidas, destaca-se a importância que as mulheres indígenas dão à diferenciação do movimento construído por elas - o qual teve grande visibilidade e consolidação na I Marcha das Mulheres Indígenas ocorrida esse ano (2019) em Brasília $^{6}$ - em relação ao feminismo branco.

A sexta e última mesa ocorreu no terceiro dia de evento e teve como tema: "Educação Indígena e a Universidade: epistemologias, circularidades e o diálogo interinstitucional". Participaram Danilo Braga, Cristiane Pankararu e Vanisse Domingos, que trouxeram releituras e problematizações do histórico de epistemicídio efetivado principalmente por meio da catequização e da educação formal estabelecida nas aldeias durante a vigência do SPI (Serviço de Proteção aos Índios). Métodos coerciti-

6 Importante destacar que tanto Nyg Kaingang como Cristiane Pankararu estavam na comissão de organização da I Marcha das Mulheres Indígenas, que reuniu mais de 3 mil mulheres indígenas pela primeira vez em Brasília, com o tema "Território: nosso corpo, nosso espírito". A previsão é de que esta marcha ocorra de dois em dois anos, tendo representado um evento de importância capital para a luta dos direitos indígenas como um todo. 
vos empregados nas escolas - como a palmatória - e conteúdos de aprendizagem - como a obrigatoriedade de decorar hinos nacionais, bem como assuntos relativos à "moral e cívica" - foram apontados como formas de violência, imposições que refletem diretamente na impossibilidade de pareamento dos conhecimentos indígenas com os conhecimentos formais e moldes não indígenas.

Nessa última mesa, foram trazidas também reflexões mais amplas sobre a educação indígena, colocando a necessidade de se pensar continuamente o processo escolar e o processo universitário. Apontou-se que os processos de construção de uma educação escolar indígena diferenciada deu passos significativos nos diferentes contextos, sendo, no entanto, percebidos de forma intrínseca aos inúmeros desafios, uma vez que o modelo escolar de ensino e aprendizado é exógeno às formas de circulação de conhecimento indígenas (as quais envolvem corporalidade, técnica, memória, oralidade, experiência dos mais velhos).

A discussão sobre a escolarização diferenciada ser uma realidade ou uma utopia culminou na importância da interlocução das comunidades indígenas com a universidade, um exercício que vem sendo empenhado por muitos professores indígenas envolvidos na construção de modelos educacionais específicos. Exemplos de educação diferenciada foram então trazidos ao debate, como aqueles praticados atualmente na TI Apucaraninha, onde o Nẽn Ga surge como um movimento feito por alunos e professores, que objetiva formação, transmissão de conhecimentos e fortalecimento da autonomia dos jovens indígenas. Colocou-se que as atividades promovidas pelo coletivo atualmente somam-se às atividades das escolas, as quais inserem em seus calendários eventos como a Festa do Pãri, na qual realiza-se a retomada de práticas, conhecimentos e técnicas Kaingang que estavam “adormecidos”, e, que hoje ganham força com investimentos e transformações contínuas da escola indígena, que somam-se a movimentos autônomos como o Nẽn Ga.

\section{Festa e ato final}

Ao final do segundo dia de debates, todos os participantes foram convidados pela organização para participar da festa de confraternização do evento, que foi realizada no espaço do alojamento. Além dos participantes que estavam ali alojados, participaram dessa festa, parte da comissão organizadora e da equipe de voluntárias -- a qual, vale destacar, também foi composta em sua maioria por mulheres. Sabe-se bem que não existe mobilização sem encontro e sem trocas. As festas são sempre momentos privilegiados para que isso aconteça, elas permitem a ampliação de redes. Além disso, claro, as festas promovem alegria. E como esta não poderia ser diferente: além de servirem comida e bebida com fartura a todos os participantes, ao longo de toda à noite as pessoas dançaram, cantaram, divertiram-se. Laércio, líder da banda e cacique da aldeia Araçaí ${ }^{7}$, animou por horas o baile que se formou pelos pares de dançarinos que, aos poucos, foram enchendo o salão. Após a apresentação da banda, a festa ainda seguiu por mais tempo, ao som da sanfona e da cantoria coletiva.

7 Laércio foi graduando de Ciências Sociais na UFPR em 2013, mas precisou se desligar do curso para assumir o cacicado em sua aldeia, cargo o qual ainda ocupa até hoje. Ele também havia sido convidado para a mesa de lideranças, porém não pôde participar. 


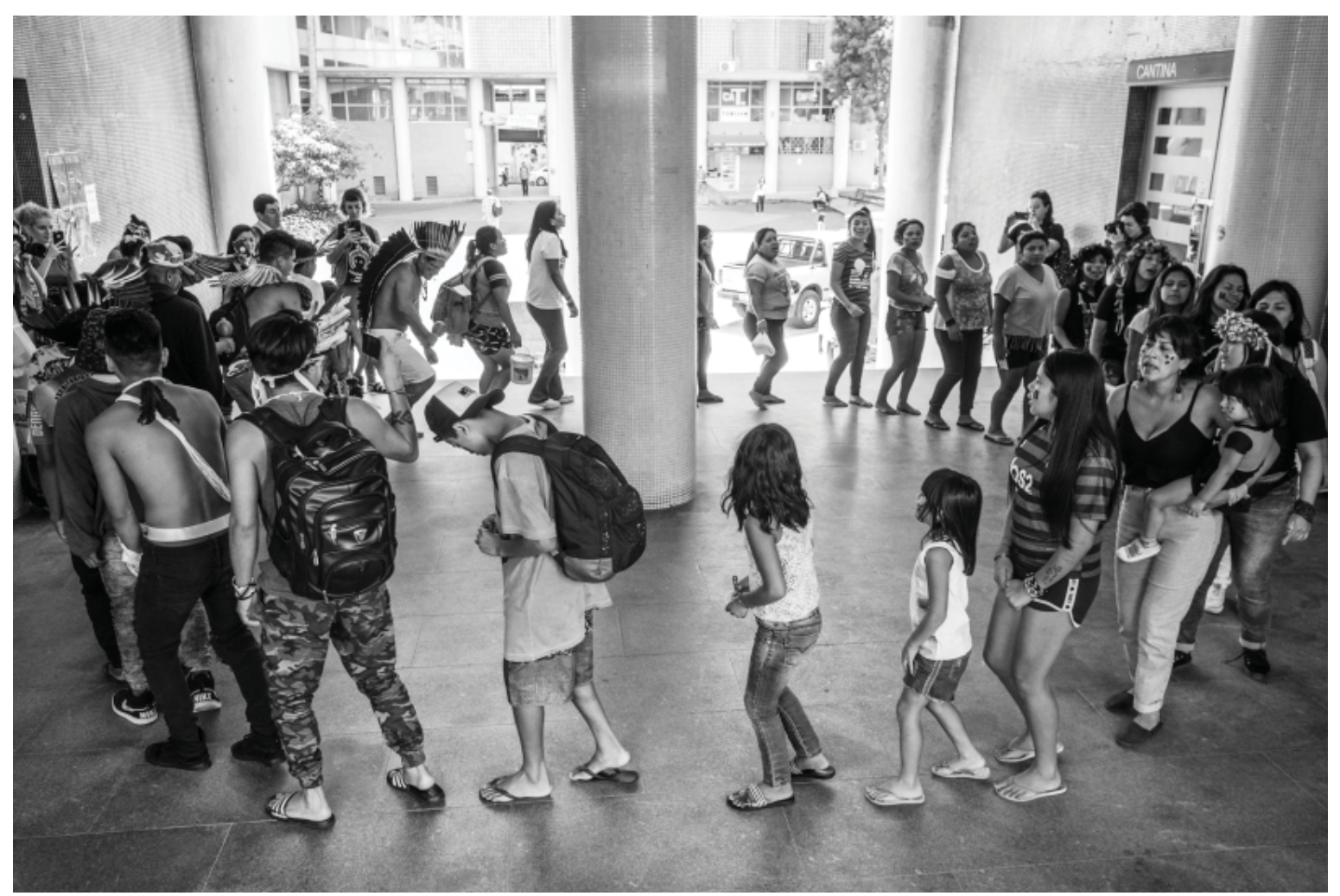

Imagem 2: Ato final

Fonte: Arquivo do MAE-UFPR. Autor Douglas Fróis, novembro de 2019

"Somos as que insistimos na festa, sem se esquecer que permanecemos em guerra". Essa frase, dita pela liderança indígena Célia Xakriabá, coloca de forma clara e pertinente a relação entre a festa - que pressupõe alegria e bem viver - e a guerra, em sua urgência e centralidade na luta constante promovida pelos povos indígenas. É uma frase que permite também conectarmos neste mesmo tópico a festa do EREI e o ato final realizado pelos participantes, no último dia do evento. Corpos vivos, que dançam e festejam, são aqueles que, também cantando, dançando, movimentando, colocam-se à frente para a luta. Não existe festa, tampouco guerra sem movimento. Assim, o ato final foi conduzido pelo coletivo Nẽn Ga, que levou todos os participantes da sala Homero de Barros aos corredores e rampas do Prédio Dom Pedro I, chegando ao saguão principal. Pintados, ornamentados, os integrantes do coletivo foram realizando seus cantos durante todo o trajeto, formando ao fim uma grande roda, enquanto outros participantes seguravam faixas com as frases "Demarcação Ja”" e "Sangue Indígena Nenhuma Gota a Mais". Esse ato atraiu jornalistas, fotógrafos, estudantes e transeuntes, ampliando significativamente a visibilidade do evento. Deixou também, de forma certeira e marcante, o recado de que a universidade é também território indígena e, como tal, deve ser ocupada por formas outras de existir, conhecer, ensinar, movimentar. 


\section{Comentários finais}

A organização e efetivação do EREI é em si expressão de um dos pontos mais enfatizados ao longo do evento: a autonomia indígena. Trata-se de um evento de mobilização, que fortalece a comunicação e a construção de redes entre os estudantes indígenas e destes com redes de comunicação e circulação mais amplas. É um evento propositivo, em que os estudantes são convocados a protagonizar suas próprias histórias, a pensar sobre seus modos próprios de transmissão de conhecimento. Enfocase a questão do ensino superior, no entanto toda a educação indígena é colocada em pauta como uma grande ferramenta para a transformação e para a luta de direitos.

A articulação com lideranças indígenas, com instituições apoiadoras, o diálogo com setores administrativos da Universidade e demais preparativos, apresentam-se como experiência de formação política aos que envolveram-se diretamente com sua organização. Além disso, os temas debatidos e os convidados para as mesas permitem que todos os participantes - em sua maioria jovens universitários indígenas - aproximem-se de questões centrais à luta por direitos empenhada pelo movimento indígena nacional. Mais uma vez, os estudantes são convocados pelas lideranças e pelos convidados mais experientes a unirem-se ao movimento indígena, a se apropriarem dos códigos, siglas e leis referentes às políticas públicas ligadas aos povos indígenas, bem como a atuarem como profissionais engajados com as questões de seus territórios de origem.

Por fim, é preciso sinalizar que o EREI é um evento de transformação da Universidade. Ao longo desses três dias, a UFPR se viu ocupada por crianças que corriam livres por seus corredores, por jovens pintados e ornamentados que cantaram e dançaram trazendo consigo a força de seus ancestrais, por mestres e lideranças indígenas que trouxeram em suas falas outras formas de ensinar e conhecer. Que essas vozes, esses corpos e esses pensamentos reverberem pelas duras paredes e compartimentos que sustentam a Universidade, abrindo espaços às pluralidades e para sua constante e urgente transformação. 


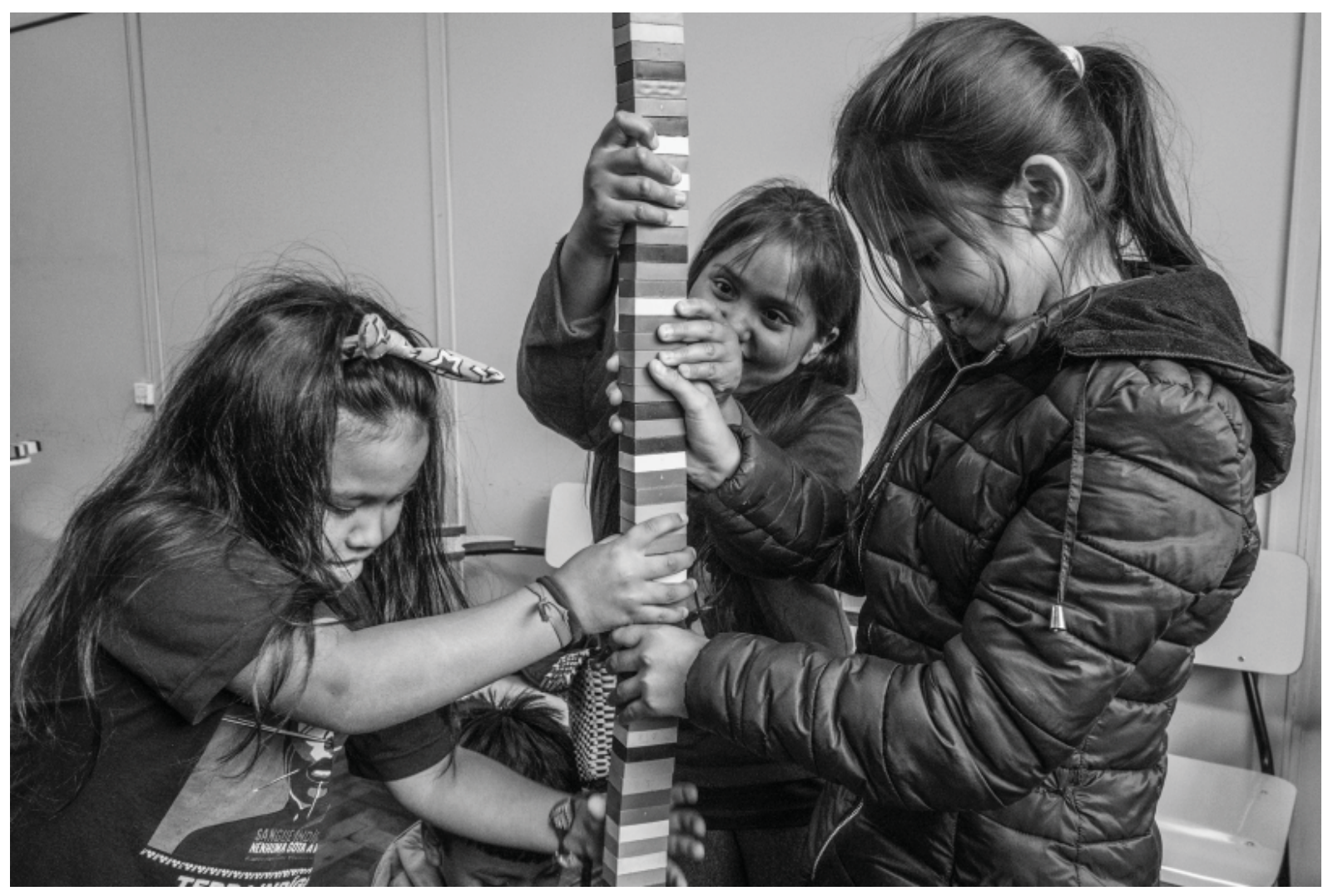

Imagem 3: Crianças na sala

Fonte: Arquivo do MAE-UFPR. Autor Douglas Fróis, novembro de 2019

Jaciele Nyg Kuitá Fidelis é graduanda em Serviço Social na UFPR.

Lays Gonçalves da Silva é mestre em Antropologia pelo PPGA/UFPR.

Paola Andrade Gibram é mestre em Antropologia pelo PPGAS/UFSC e doutoranda em Antropologia no PPGAS/USP.

RECEBIDO: $09 / 12 / 2019$

APROVADO: $06 / 02 / 2020$ 